\title{
Numerical and Experimental Study on Tooth Filling via near Net Shape Extrusion-Forging Process of Multicore Cable Cutter
}

\section{Chih-Chun Hsu}

NCU: National Central University

Huan-Yu Chiu

NCU: National Central University

Chi-Peng Chen

NCU: National Central University

Chien-Chou Liaob

hanlong industrial Co.

Yiin-Kuen Fuh ( $\nabla$ michaelfuh@gmail.com )

NCU: National Central University

\section{Research Article}

Keywords: Finite element method, tooth filling, near net shape, extrusion-forging, Evaluation index

Posted Date: May 28th, 2021

DOI: https://doi.org/10.21203/rs.3.rs-497762/v1

License: (c) (1) This work is licensed under a Creative Commons Attribution 4.0 International License. Read Full License 


\section{Abstract}

The near net shape extrusion-forging and the impact of tooth filling computationally simulated and experimentally corroborated. The study plans to search for the finishing forging process's essential station and recognize the unique gear teeth forming in the closed die near net shape extrusion-forging connected with a multicore cable cutter. Due to make sure to realize the Preform types of gear teeth forming, The evaluation index of the height filling ratio (HFR) and the width filling ratio (WFR) methods are offered and simulated with a singular target on process parameters at the gear teeth making. All the objects are regularly investigated and precisely contrasted to experimental examination. The simulations' conclusions have explained the microscopic events after the experimental research. Via matching with experimental measurements, the accuracy of the numerical models has been confirmed. The offered modified geometries (Preform B and C) from the forming process have been eventually offered to achieve a resembling forming condition while lessening making charges.. The mean deviation of HFR was measured as $0.987 \%$ and $0.985 \%$ for Preform B and C, respectively. Moreover, the mean deviation of WFR was calculated as $-0.693 \%$ and $-0.74 \%$ for Preform B and C, separately.

\section{Introduction}

The gear hot forging process was previously conducted to reduce the forging force, and the optimal design parameters were established to minimize its variation. [1] For example, hot Forging of Automobile Steel Gear Blanks has explored such that the compromises between contraction of the underfill dimension as well as the flash surplus material) was illustrated. [2] On the studied materials for gear forming, magnesium alloy AZ31B spur bevel gear Hot forging process was conducted, and compared the experimental load-stroke curves with the calculated ones. [3] In addition, investigation on bi-metal gear hot forging process with particular focus on metal flow and forming load and the results showed the relative flow of two metals and different ring thicknesses significantly influence the structure of the bimetal gear[4]. Another deformation law during the dual directional hot forging of the steel-aluminum spur gear indicated the final forging temperature of billet increases, and the forming load decreases with the increasing the forging speed.[5]One of the crucial pieces of research on gear tooth forming control of spiral bevel gear illustrated the effectiveness of enhancing the forging quality and decreasing the scrap rate of the forged spiral bevel gear. [6]

Computer applications such as CAD/CAM/CAE, primarily based on FEM (Finite element method), are used to design, analyze, and optimize metal forming processes, including the forging process. Primarily it can be executed to various process and device design for the correct prediction of the deformation performance in a wide range of gear shapes and applications such as straight bevel gear[7], non-circular gears[8], Idle Gear [9], industrial locking gear [10], aircraft landing gear [11]. Furthermore, numerical analysis and experimental validation on the multi-stage warm forging process of deep groove ball bearing were investigated with microstructure and defect analysis [12]. The accuracy of the numerical models has been verified by comparing them with experimental measurements. Several novel process innovations had been proposed with a feasible formation process of precision gears. For example, hot 
forging-upsetting finishing-radial extrusion of conjunction gear [13]and, in particular, deformation mechanism of non-standard gear teeth forming in the hot impression forging of multicore cable cutter [14] showed a valuable advancement and valuable technological reference for the forging special gears connected with any geometry. Furthermore, A new "cold forging after quenching and tempering" (CFAQT) process was proposed with the benefit of shortening the process chain via avoiding subsequent heat treatment distortion and cost-reduction. [15]

A new net shape extrusion-forging process is offered to apprehend the multicore cable cutter gear shape forming and supplant conventional investment casting. The finite element tool QForm was used to simulate the gear forming process. The net shape extrusion-forging parameters, especially at the joined net shape extrusion-forming of gear form, are regularly investigated. Further, the different forging preform geometry is offered to complete a resembling forming situation. The numerical simulations made to contrast the actual parameters and experimentally validated the justifiability.

\section{Assembly Of Multicore Cable Cutter With Controlled Deformation 3.1 Multicore cable cutter with forged movable and fixed blade}

The applications of investigated multicore cable cutter researched in this article can be functionally specified with multicore cable cutter gear profiles of the movable blade (red rectangle) and fixed blade (blue rectangle), which was made of AISI-1040 steel as presented in Fig. 1. Two gears drive the actuated device of the multicore cable cutter to drive the teeth on the movable blade forward-the portion formed by the movable blade and the fixed blade gradually reduced to achieve the shearing effect. The gear pushes the teeth on the movable blade with a plurality of latching teeth so that the pushing force on the latching teeth can spread. This makes latching teeth not easy to damage, and the service life of the cable cutter can be extended. The multicore cable cutter gear has many functions due to its customized multicore cable cutter, including 1.Rapidly release mechanism allows the blade to be quickly reset 2.Constant velocity ratchet mechanism is used to reduce the strength of manual cutting 3.Manual locking mechanism makes it safer to use.

\subsection{Deficiencies investigation of investment casting}

A precision casting process makes the traditional cable cutter. However, due to the difference in geometrical thickness of the product (aspect ratio > 100), it is easy to cause defects such as pore cracking. It will result in the product's poor mechanical properties, and the entire processing process takes a long time, and the production cost is high. The related dewaxing will cause many defects, as shown in Fig. 2(a), and the defect microstructure will be observed in Fig. 2(b) - 2(d). As shown in Fig. 2(b), there are many different size hole defects and cracks in the red region. This is the pore cracking caused by dewaxing casting, as shown in Fig. 2(c). Furthermore, Fig. 2(d) shows that the blue region has a defect of 
$\sim 3 \mathrm{~mm}$. The crack has been produced when the dewaxing is completed and will not be affected by the production's advancement to increase the number of cracks.

The actual process of precision toothed cable clamp and precision hand tool forging tooth is mainly precision casting. The dewaxing process will cause many defects, mainly in the form of pores. It also has a significant impact on subsequent heat treatment and related mechanical cutting processes. After surface polishing and bottom milling $2 \mathrm{~mm}$ (to eliminate the flash and show the cutting edge), the workpiece is shown in Fig. 3(a). Even after the surface polishing and bottom milling, the workpiece still has defects in the blue region and red region, as shown in Fig. 3(b). The defect microstructure can be observed by electron microscopy, as shown in Fig. 3(c) - 3(d). They have $4 \mathrm{~mm}$ defects and $3.5 \mathrm{~mm}$ defects in the blue region and redregion,respectively.

The instrument construction used for the last forging processes and production stages of the adjustable blade's near net shape extrusion-forging process was shown in Fig. 4. The die of gear tooth forging the adjustable blade and comparing it with the numerical model was shown in Fig. 4(a). Besides, Fig. 4(b) compares the flattening forging die with the numerical model. The forging dies were built by a collaborative company and fitted on a $350 \mathrm{kN}$ hydraulic testing device. At the near net shape extrusionforging process of the multicore cable cutter gear, the forming dies were heated up to $200 \pm 20^{\circ} \mathrm{C}$ in advance, and the high-temperature lubrication was water-based graphite lubricant. The billet was heated up to $1000 \pm 10^{\circ} \mathrm{C}$ forging to the adjustable blade by forging dies. The experimentally forged commodities are matched with the simulation analysis outcomes to confirm the precision and workability. Figure 4(c) - 4(d) shows a matching of the experimental and simulated outcomes. Figure 4(c) explains the experimental results matched with the preform simulation results.

The comparison explains that the experimental results' gear tooth is very close to the simulation analysis results. After forming experiments, the components were chilled to room temperature in the air.

Figure 5 presents the tooling forging structure and production stages of the near net shape extrusionforging process design of the fixed blade. Concerning the ease of the mold release and efficacy of the subsequent process, machining allowances at the flash areas are $2 \mathrm{~mm}$ thickness. Similarly, Fig. 5(a) shows the fixed blade forging die and compares it with the numerical model. Moreover, Fig. 5(b) compares the flattening forging die with the numerical model. In order to construct a dimensional model, SolidWorks software was being used. Design factors including forming shape, pattern sketch, inside and outside fillet, forming tolerance, finish allowance, Etc. That needs to be considered for the forging design. Furthermore, according to the forging shape, the forming die was designed.. Figure 5(c) shows the numerical (left) and experimental (right) outcomes of the laser cutting preform of a fixed blade. Numerical simulation was performed by using the commercial FE code, QForm. QForm forging process simulation analysis software covers almost the forging process of metal volume forming. Comparing the experimental results and simulation results of finish forging is shown in Fig. 5(d), which shows a striking resemblance both in geometrical material filling and the flash location. The flash part reveals the actual positions, while the three protrusions marked the positions for knock-out areas. The carbon steel S45C 
and JIS SKD61 die steel is used for all the workpiece and near net shape extrusion-forging dies, respectively.

In this study, three different preforms for the forging workpieces were proposed, as shown in Fig. 6. Three different preforms of multicore cable cutter gear with Preform A of extrusion process (a), Preform B with the initial gear tooth of $2 \mathrm{~mm}$ thick on forging workpiece (b), and Preform $C$ without gear tooth on forging workpiece (c). Besides, numerical simulation improves and optimizes mold design by simulating issues that happen during the forming process. Preform $A$ is the traditional forging perform as shown in Fig. 6(a). It can be seen that the gear tooth is extruded from the forging workpiece. Preform $B$ is the novel extrusion-forging teeth perform with the gear tooth on forging workpiece as shown in Fig. 6(b). Finally, the preform $\mathrm{C}$ forging method is the same as preform $\mathrm{B}$, but there is no gear tooth on the forging workpiece, as shown in Fig. 6(c).

The forming load results in the different preforms illustrated in Fig. 7. The differences in the forging loads are apparent under the three different forging preforms. It can be observed that Preform A has the most considerable forging load, and the maximum forging load is up to $6.06 \mathrm{MN}$. The forming loads of Preform $B$ and Preform C are 4.05 and 3.97, respectively. Preform A's forming load is much greater than the other two preforms compared with Preform B and C. Therefore, Preform A's design is not included in the followup discussion. The differences in the simulation analysis of Preform $B$ and $C$ will be discussed behind. Finally, a preform that is best suited for the manufacture of gear tooth will be selected.

Preforms $B$ and $C$ reached a final deformation state of $100 \%$ stroke during simulated forging, as shown in Fig. 8(a). Two different preforms can be observed, all of which can simulate a complete tooth profile. In Fig. 8(b), the effective stress distribution simulation of the Preform $B$ precision-machined forged workpiece reaches $120 \mathrm{MPa}$ or more, and the maximum stress reaches about $300 \mathrm{MPa}$. Preform C's effective stress distribution is simulated to reach $100 \mathrm{MPa}$ or more, and the maximum stress is about 280 $\mathrm{MPa}$. When the deformation process is completed, the maximum strain of Preform B reaches about 11, and the maximum strain of Preform $\mathrm{C}$ reaches about 9.5, as shown in Fig. 8(c). As the above mold progresses, the plastic deformation of the gear teeth (especially the burr area) increases, and since the metal flow resistance in the complex tooth profile is considerable, effective strain accumulates in the gear tooth cavity. During the forging stages, both Preform B and C plastically deformed in the gear corner's vicinity such that the maximum deformation occurs in the flash region of the bottom die. After forging, the workpiece temperature increases with increasing pressure, the maximum temperature for Preform $B$ was up to $1100^{\circ} \mathrm{C}$, and the maximum temperature for Preform $\mathrm{C}$ was up to $1080^{\circ} \mathrm{C}$, as shown in Fig. 8(d). The workpiece's surface temperature is significantly reduced due to the heat transfer from the lubricant between the workpiece and the mold. Finally, it can be found that the maximum value of stress, strain, and temperature, the Preform C is slightly lower than the Preform B, but there is not much difference in the simulated distribution.

The schematic diagram on the tooth dies (Preform B and Preform C) shows in Fig. 9. Figure 9(b)shows the differences in effective stress for forging processes between Preform B and C. In terms of the stress 
values, the tooth die requires the maximum force during the forging process. Nevertheless, the maximum effective stress of the two performs similarly, which is more than $1600 \mathrm{MPa}$. It is because of the high metal flow resistance on this part. Therefore, there is a severe deformation in this area.

Figure 10(a) shows the distributions of the forging temperature of Preform B and C. The workpieces' temperature was increased by Local large deformation. Furthermore, the high temperature will reduce the service life of tooth die. At Fig. 10(a), the maximum average temperature of Preform B is $513.05^{\circ} \mathrm{C}$ higher than Preform $C$ (the maximum average temperature is about $506.9^{\circ} \mathrm{C}$ ). From these results, Preform $\mathrm{B}$ and C's temperatures are roughly the same, which means both preforms have a similar deformation mechanism while the Preform $\mathrm{C}$ can be relatively obtainable through the delicate blanking process.

The displacement vector distributions for Preform B and C was displayed in Fig. 10(b). At the gear's summit of the workpiece's displacement vector is evident, which indicates the flash-forming procedure is the last forging moment. The tooth's maximum displacement vector of Preform $B$ is $0.1416 \mathrm{~mm}$, shown in Fig. 10(b), and the flash area's velocity is similar. Likewise, the maximum vector of Preform $C$ is 0.1546 $\mathrm{mm}$. In Fig. 10(b), the average displacement vector of tooth both Preforms $B$ and $C$ is similar, which means there is just a slight deformation at the workpiece's gear. Hence, Preform $C$ was chosen for the near net shaped extrusion-forging process of adjustable gear device because the company will save more expense about laser cutting procedures for Preform B at the initial gear protrusion.

The evaluation index of forming and the resultant of forming quality can be used as the objective functions, particularly in the gear forming section. Figure 11(a) shows the Schematic region on the forging workpiece and schematic location on the gear tooth. The evaluation index of the height filling ratio (HFR) and the width filling ratio (WFR) of the formed gear on preform $B$ and preform $C$ has shown in Fig. 11(b) -11 (c), respectively. The complex formula for calculations of forming index was similarly performed as follows [?].

(1) The height filling ratio $H F R=\frac{H_{s}}{H_{g}} . H_{S}$ is the height of filling section of the workpiece; $H_{g}$ is the designed height of gear toothed die.

(2) The width filling ratio filling ratio $W F R=1-\frac{w_{s}}{w_{g}}$ is the the designed width of gear toothed die.

The HFR and WFR analysis outcomes explain in Fig. 11(B) and Fig. 11(C). The ideal height filling ratio of tooth top of experimental gear blade is $\mathrm{Hg}$ ( from 6.3 to $6 \mathrm{~mm}$ ), the maximum minus-deviation for Preform B and C is $-0.02 \%$, the mean deviation for Preform B is $0.987 \%$, the mean deviation for Preform C is $0.985 \%$. On the other hand, the width filling ratio of tooth top of experimental gear blade is $\mathrm{Wg}$ (from 1.25 to $1 \mathrm{~mm}$ ), the highest minus-deviation is $-0.19 \%$, and the mean deviation is $-0.693 \%$ for Preform $B$, and the highest minus-deviation is $-0.17 \%$. The mean deviation is $-0.74 \%$ for Preform $\mathrm{C}$. That implies the mean deviation of both HFR and WFR for Preform B and C is essentially identical. 
Due to understand the microstructure's forging and the change of the forging line, the workpiece was cut by an electric discharge machining (EDM) wire cutter, and it was cut along the region $A \sim F$ as shown in Fig. 12(a). The workpiece was ground and polished, corroded by the corrosive liquid mixed with $0.7 \%$ picric acid and $9.3 \%$ alcohol. The corrosion time is controlled to be about $15 \sim 20$ seconds. After the corrosion, the surface is rinsed with water and dried to observe the metallographic microstructure and forge a line on the forging surface. Figure 12(b) shows the results of the forging line after simulation. Comparing the actual situation with the simulation results, the two are almost identical, especially in the $\mathrm{E}$ and $\mathrm{F}$ regions, and it is more evidence that they are similar. No forging line wrinkles were observed in the experiment, and the forging line was continuously continuous in the area where the forging was severely changed, which indicates that the forging process has a good design.

Lastly, An optical micrograph (OM) was used to research the forged product's microstructure analysis. A schematic picture of the forged gear tooth is shown in Fig. 13 (a). The OM micrograph of region I, region II and region III is shown in Fig. 13(b) - 13(d), respectively. Binarization of initial OM images converts grayscale into binary ones. The grain radius was calculated using MATLAB as $14.63,9.78$, and $12.71 \mu \mathrm{m}$ for region I, region II and region III.

\section{Conclusion}

This article numerically analyzes 3D FEM of near net shape extrusion-forging. Simulation data for the forming process design, including forming load, effective plastic strain/stress distribution, and temperature conditions. The following outcomes can be summarized:

1. Three different preforms of multicore cable cutter gear for the forging workpieces were proposed. The forming load results show the maximum forming load of Preform $A$ is up to $6.06 \mathrm{MN}$, and the forming loads of Preform B and Preform C are 4.05 and 3.97, respectively. Therefore, in this study, the differences in the simulation analysis of Preform $B$ and $C$ were discussed to select the best suited for the manufacture of the gear tooth.

2. Three improved preform are proposed in this study. The simulation outcomes show the maximum stress for Preform B and C are $300 \mathrm{MPa}$ and $280 \mathrm{MPa}$, respectively. Preform B's maximum strain reaches about 11, and the maximum strain of Preform $C$ reaches about 9.5. The maximum temperature for Preform $\mathrm{B}$ was up to $1100^{\circ} \mathrm{C}$, and the maximum temperature for Preform $\mathrm{C}$ was up to $1080^{\circ} \mathrm{C}$.

3. The evaluation index of the height filling ratio (HFR) and the width filling ratio (WFR) of Preform $B$ and $\mathrm{C}$ is proposed and simulated to explain the results of forming quality. The mean deviation of HFR was calculated as $0.987 \%$ and $0.985 \%$ for Preform B and C, respectively. The mean deviation of WFR was calculated as $-0.693 \%$ and $-0.74 \%$ for Preform $B$ and C, respectively. That means the mean deviation of both HFR and WFR for Preform B and C is almost experimentally identical in term of material filling.

4. According to the $\mathrm{OM}$ microstructure analysis, the grain radius of region I, region II and region III were measured separately. Furthermore, the results were calculated by MATLAB as 14.63, 9.78, and 
$12.71 \mu \mathrm{m}$, individually.

5. Finally, it can be found from compared Preform $B$ and $C$ that the maximum value of stress, strain, and temperature, the Preform $C$ is slightly lower than the Preform $B$, but there is not much difference in the simulated distribution.

\section{Declarations}

\section{Ethical approval}

Since the study is performed at a relevant lab, there is no need for ethical approval. Additionally, the paper's main data is not published elsewhere.

\section{Consent to participate}

All authors declare that have agreed for authorship, have read and approved the manuscript, and have given the consent for submission and subsequent publication of the manuscript.

\section{Consent to publish}

All authors are consenting to publish this article with its included data in The International Journal of Advanced Manufacturing Technology and approve its final version.

\section{Authors' contributions}

All authors contributed equally to the generation and analysis of experimental data, and the development of the manuscript.

\section{Funding}

This work was financially funded by Hanlong Industrial Co., Ltd.

\section{Competing interests}

The authors declare that they have no competing interests.

\section{Availability of data and materials}

The authors confirm that the data supporting the findings of this study are available within the article.

\section{References}

[1] Chen, X., \& Jung, D. Gear hot forging process robust design based on finite element method. Journal of Mechanical Science and Technology 2008; 22:1772-1778. 
[2] Ahmed, S., Goh, C.-H., Allen, J. K., Mistree, F., Zagade, P., \& Gautham, B. P. Hot Forging of Automobile Steel Gear Blanks: An Exploration of the Solution Space. Mater Des 2014;2:2014-34197

[3] Liu, J., \& Cui, Z. Hot forging process design and parameters determination of magnesium alloy AZ31B spur bevel gear. Journal of Materials Processing Technology 2009;209:5871-5880

[4] Wu, P., Wang, B., Lin, J., Zuo, B., Li, Z., \& Zhou, J. Investigation on metal flow and forming load of bimetal gear hot forging process. Int J Adv Manuf Technol 2016;88:2835-2847.

[5] Feng, W., Jia, X., Liu, B., \& Gao, M. Material flow characteristics and deformation law during dual directional hot forging of the steel-aluminium spur gear Procedia Manufacturing 2020;50:425-428.

[6] Gronostajski, Z., Kaszuba, M., Polak, S., Zwierzchowski, M., Niechajowicz, A., \& Hawryluk, M. The failure mechanisms of hot forging dies. Materials Science \&Engineering A 2016;657:147-160.

[7] Khalilpourazary, S., Dadvand, A., Azdast, T., \& Sadeghi, M. H. Design and manufacturing of a straight bevel gear in hotprecision forging process using finite volume methodand CAD/CAE technology. Int J Adv Manuf Technol 2011;56:87-95.

[8] Doege, E., Meinen, J., Neumaier, T., \& Schaprian, M. Numerical design of a new forging press drive incorporating non-circular gears. Journal of Engineering Manufacture 2001;215:465-471.

[9] Soranansri, P., Sukpat, M., Pornsawangkul, T., Mungsantisuk, P., \& Sirivedin, K. Effect of Preform Height on Die Wear in Hot Forging Process of Idle Gear by Finite Element Modeling. Key Engineering Materials 2017;728;36-41.

[10] M. Maarefdousta and M. Kadkhodayan. Simulation and analysis of hot forging process for industrial locking gear elevators. Applied Mechanics and Mechanical Engineering 2010;14:1-10

[11] Ram Prabhu, T. Simulations and Experiments of Hot Forging Design and Evaluation of the Aircraft Landing Gear Barrel Al Alloy Structure. Journal of Materials Engineering and Performance 2016;25:12571268.

[12] Hsu, C.-C., Huang, J.-H., Chen, W.-C., \& Fuh, Y.-K. Numerical analysis and experimental validation on multi-stage warm forging process of deep groove ball bearing-a modified punch geometry with microstructure and defect analysis. Int J Adv Manuf Technol 2016;89:2119-2128.

[13] Li, S., Ji, H., Wang, B., \& Mu, Y. Numerical analysis and experimental validation of conjunction gear via hot forging-upsetting finishing-radial extrusion. Archives of Civil and Mechanical Engineering 2019;19:391-404. 
[14] Hsu, C.-C., Chiu, H.-Y., Liao, C.-C., \& Fuh, Y.-K. An investigation on deformation mechanism of nonstandard gear teeth forming in the hot impression forging of multicore cable cutter. Journal of Manufacturing Processes 2020;54:158-168.

[15] Hu, C., Zhao, Z., Gong, A., \& Shi, W. Study of an Alternative Novel Cold Forging Process. Materials and Manufacturing Processes 2015;30:1210-1217.

\section{Figures}
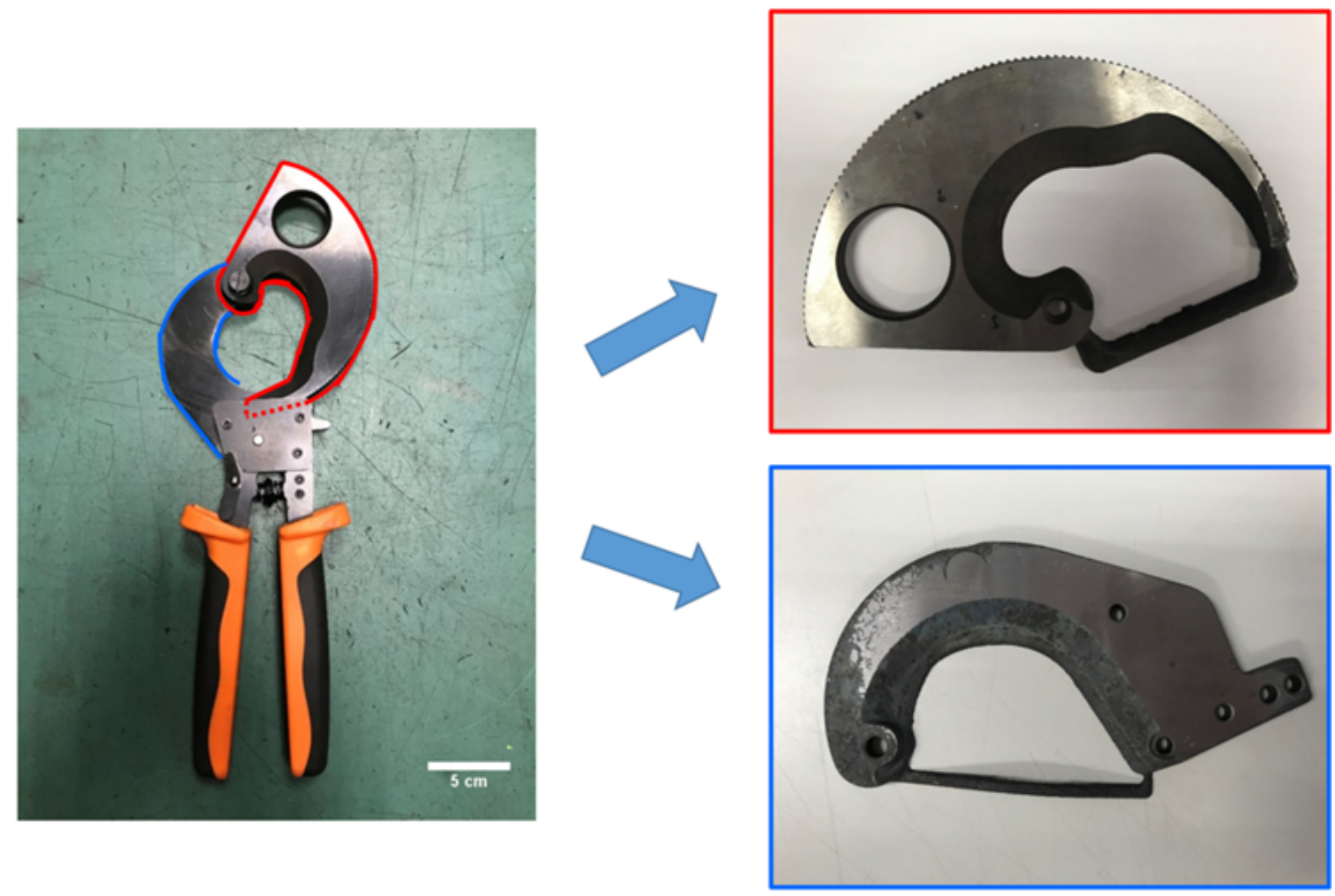

\section{Figure 1}

Structure of the multicore cable cutter gear and it compose of movable blade (red rectangle) and fixed blade (blue rectangle). Scale bar: $5 \mathrm{~cm}$ 
(b)

(a)

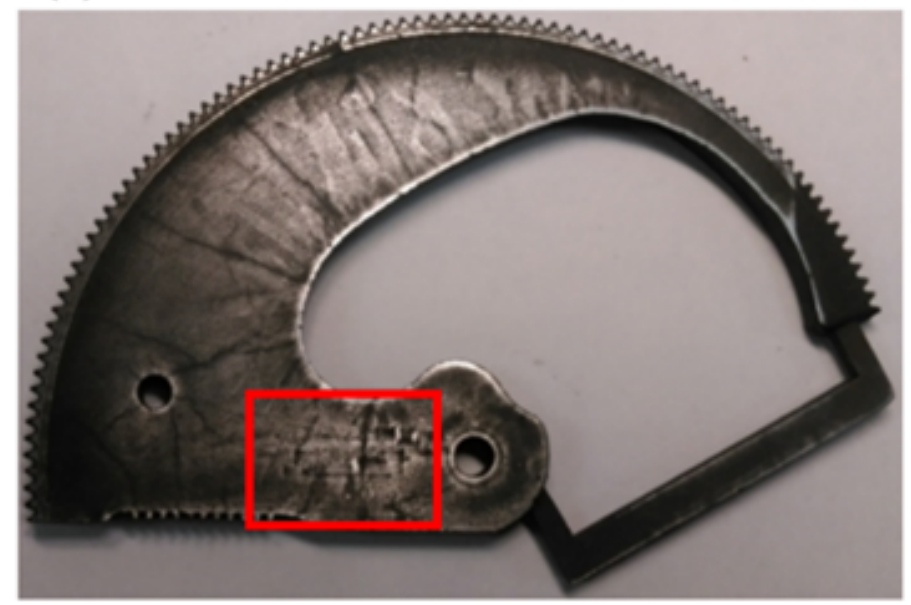

(c)

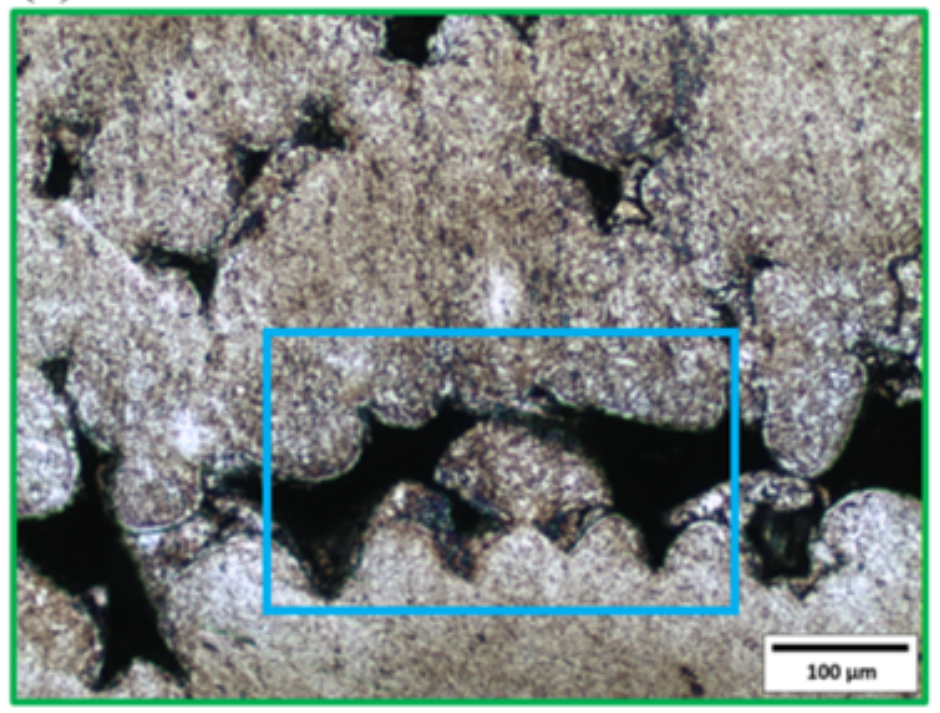

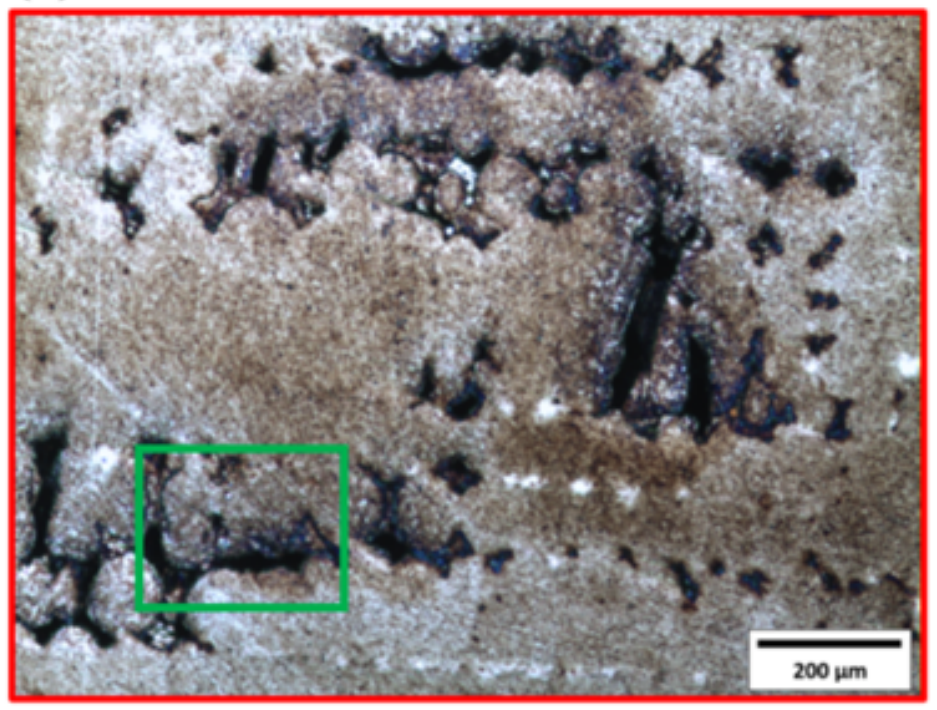

(d)

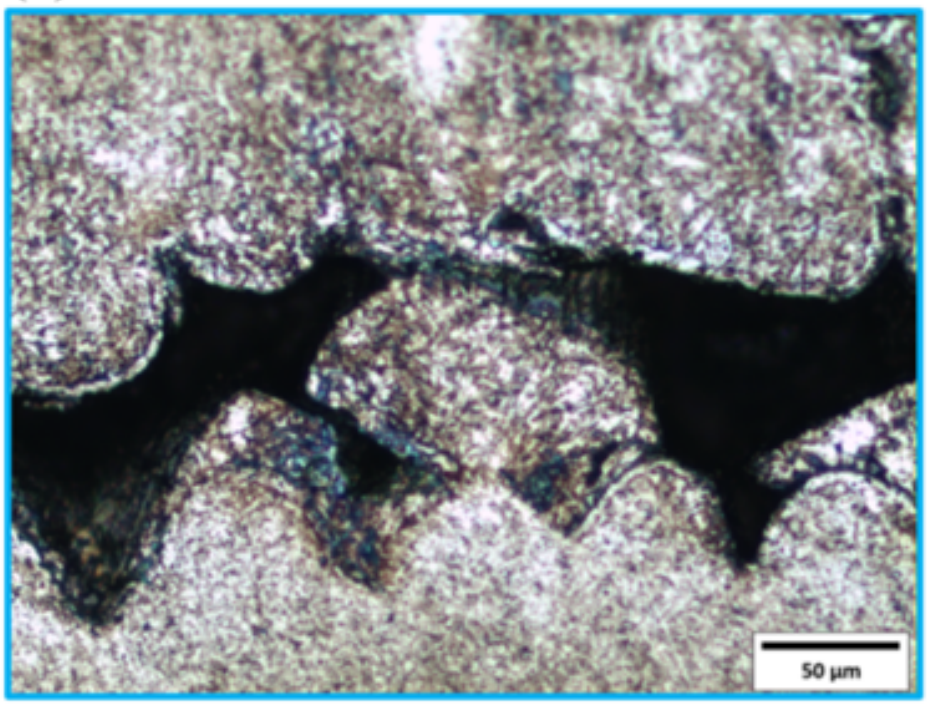

Figure 2

(a) The investment casting of the multicore cable cutter gear. (b) The microstructure at the red area $(\times 50)$.

(c) The microstructure at the green zone $(\times 100)$. (d) The microstructure at the blue area $(\times 200)$. 
(a)
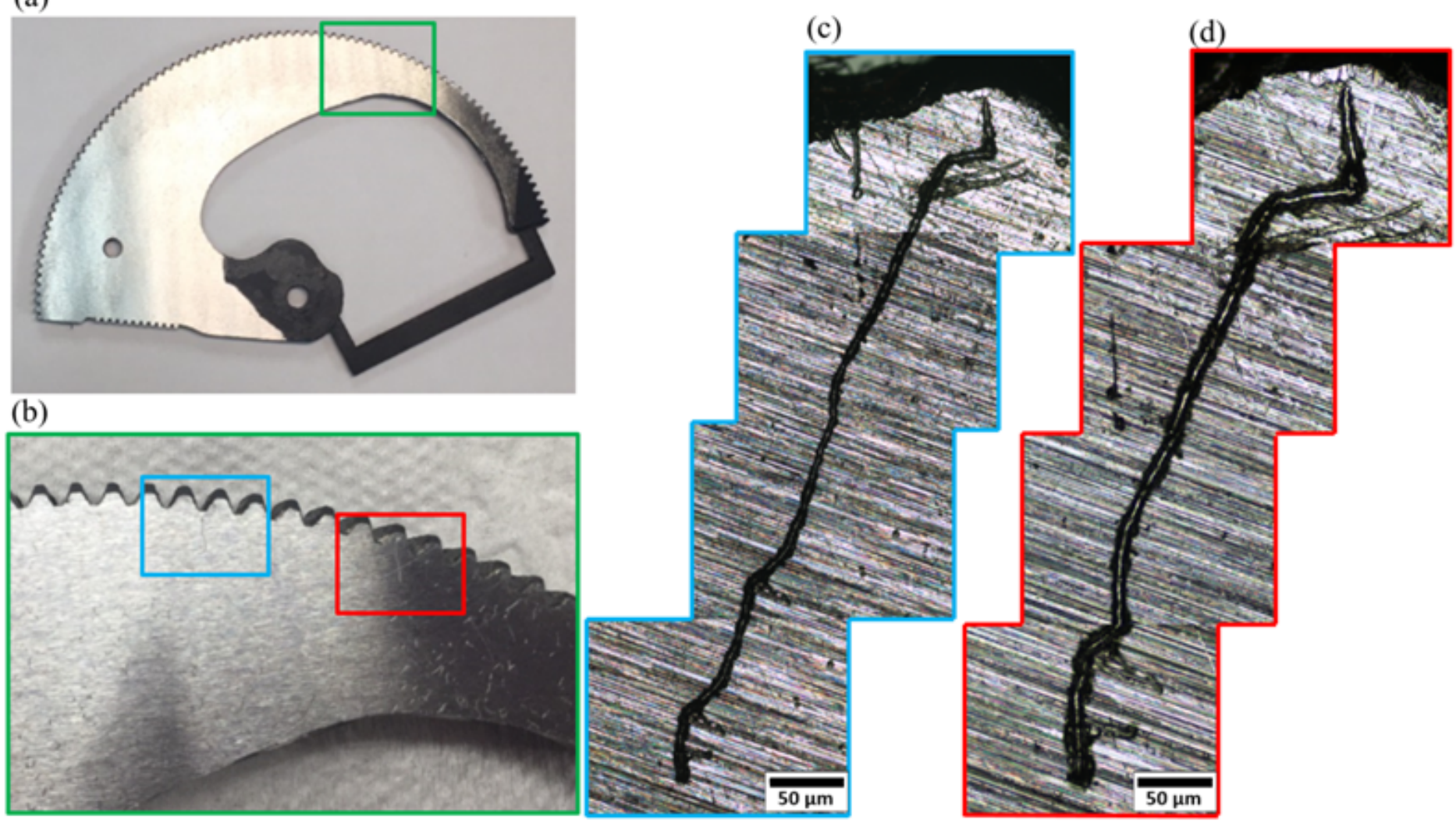

(b)

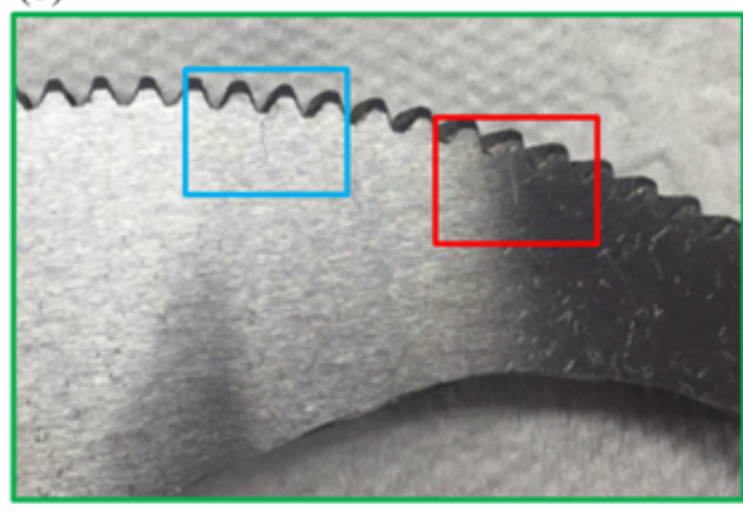

Figure 3

(a) The investment casting of the polished multicore cable cutter gear. (b) The green area of the multicore cable cutter gear has a deficiency right on the blue oblong and red oblong. (c) The microstructure at the blue region and has a $4 \mathrm{~mm}$ defect $(\times 200)$. (d) The microstructure at red region and has a $3.5 \mathrm{~mm}$ defect $(\times 200)$ 

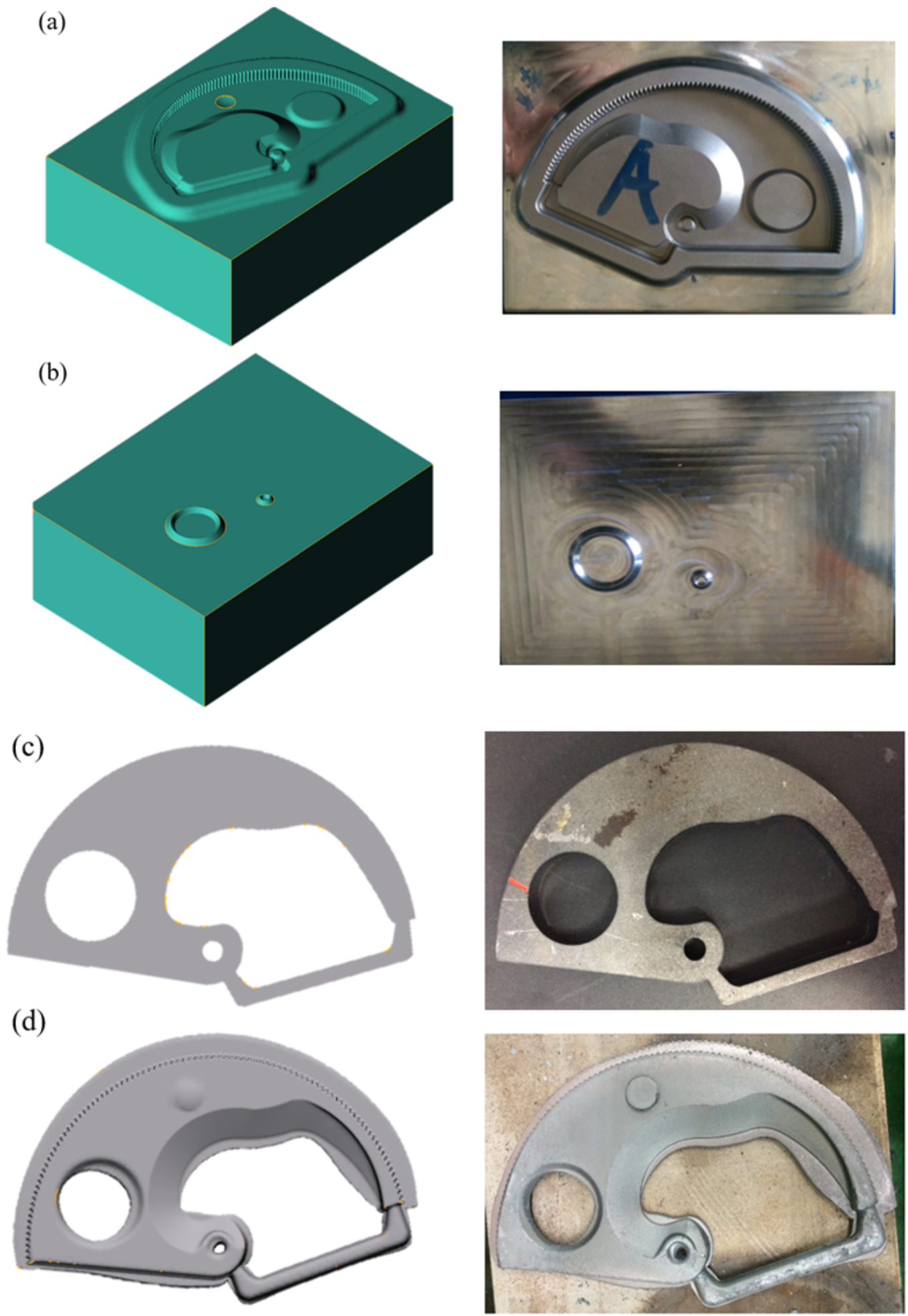

\section{Figure 4}

Tooling forging structure of the multicore cable cutter gear and forming stages of near net shape extrusion-forging process design of movable blade. (a) Gear tooth die. (b) Flattening die. (c) Laser cutting preform. (d) Finish forging. 

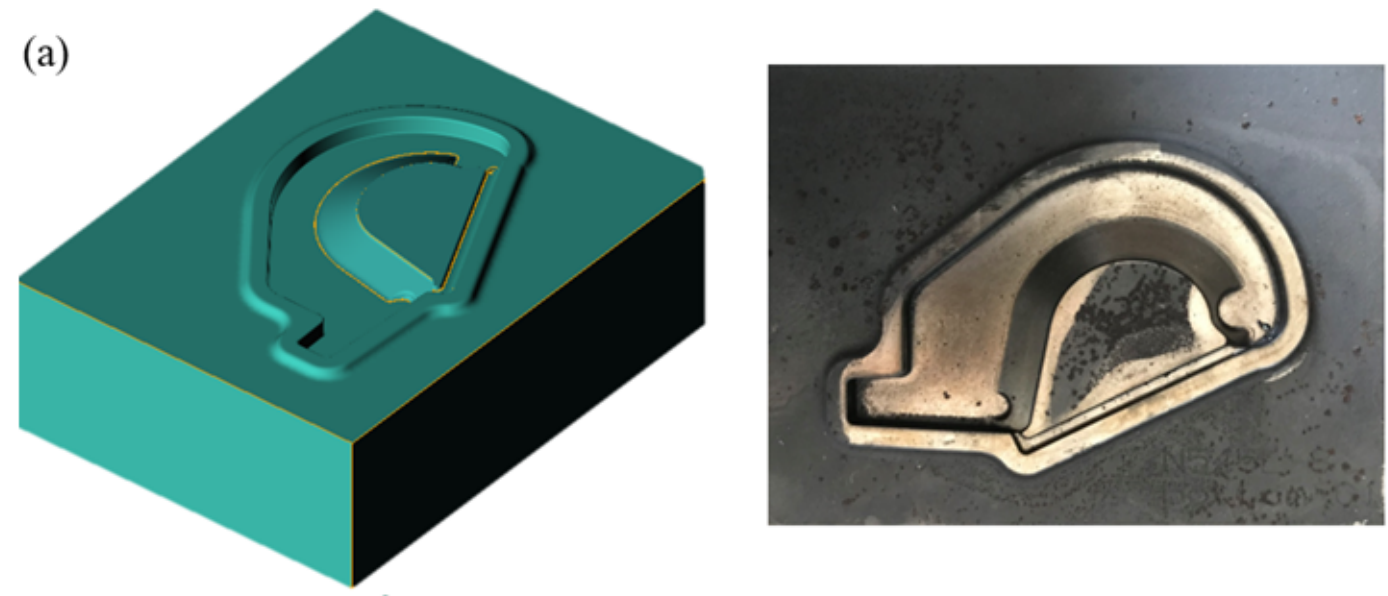

(b)
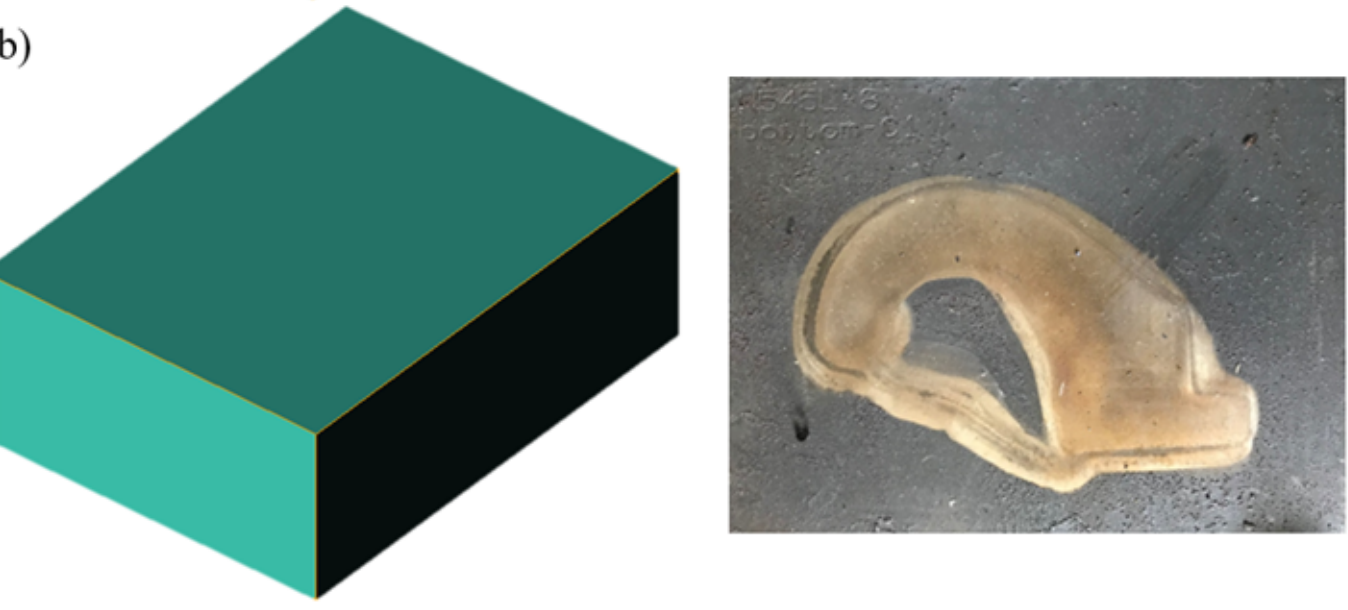

(c)
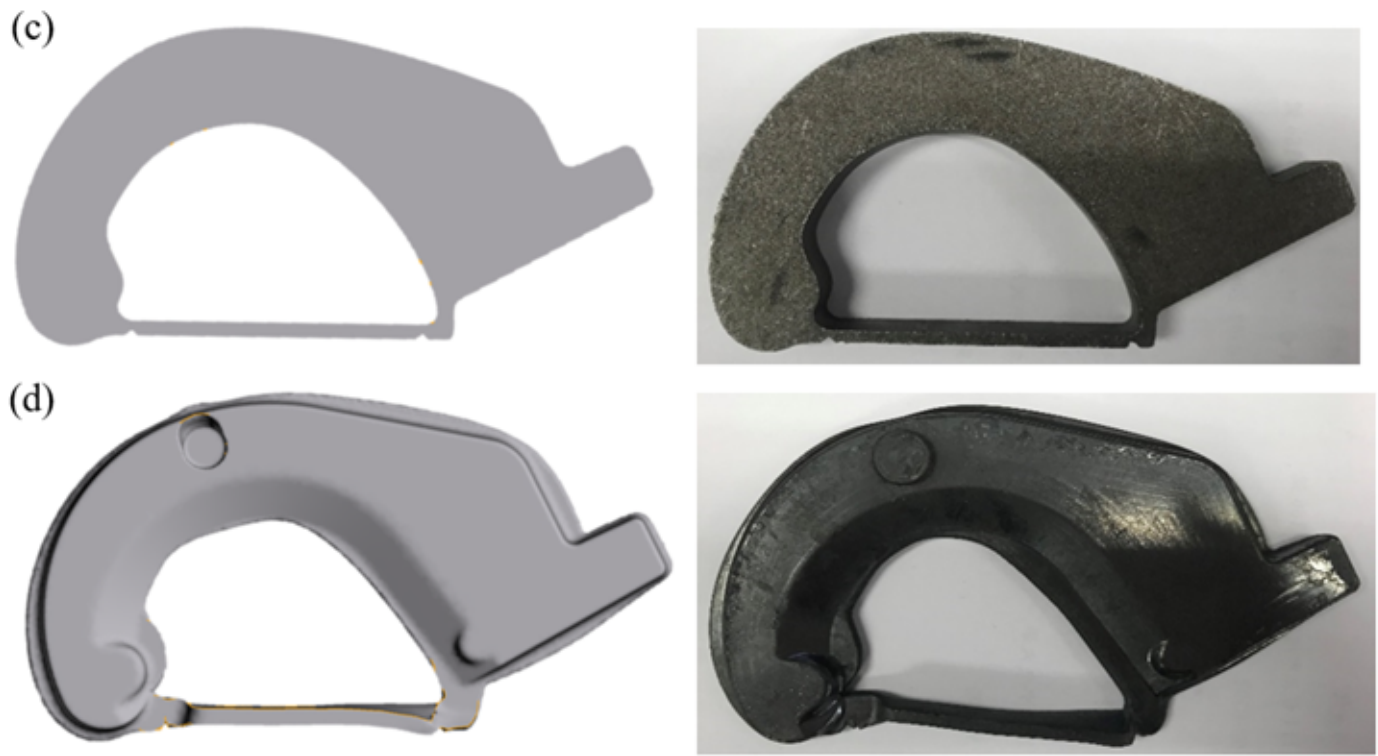

\section{Figure 5}

Tooling forging structure and production stages of near net shape extrusion-forging process design of fixed blade. (a) Fixed blade die. (b) Flattening die. (c) Laser cutting preform of fixed blade. (d) Finish forging of fixed blade. 
(a)

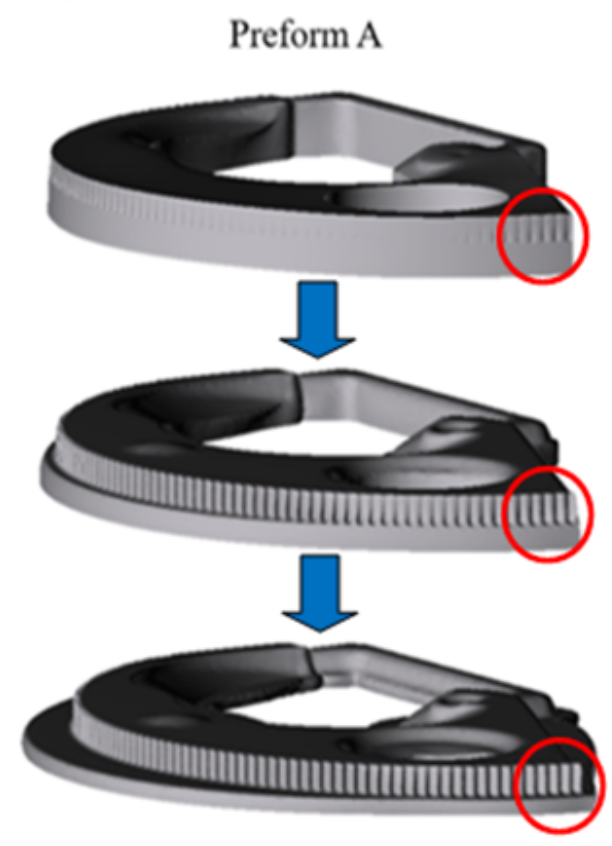

(b)

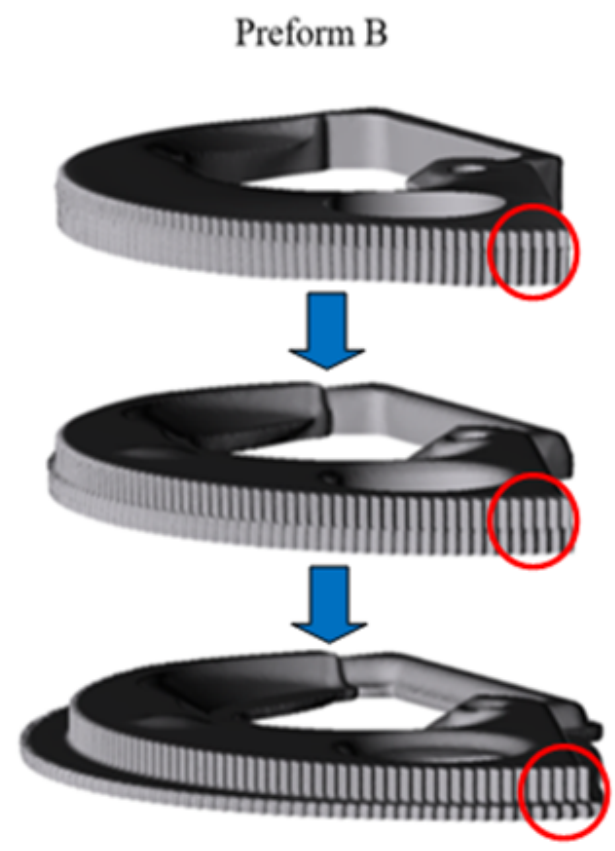

(c)

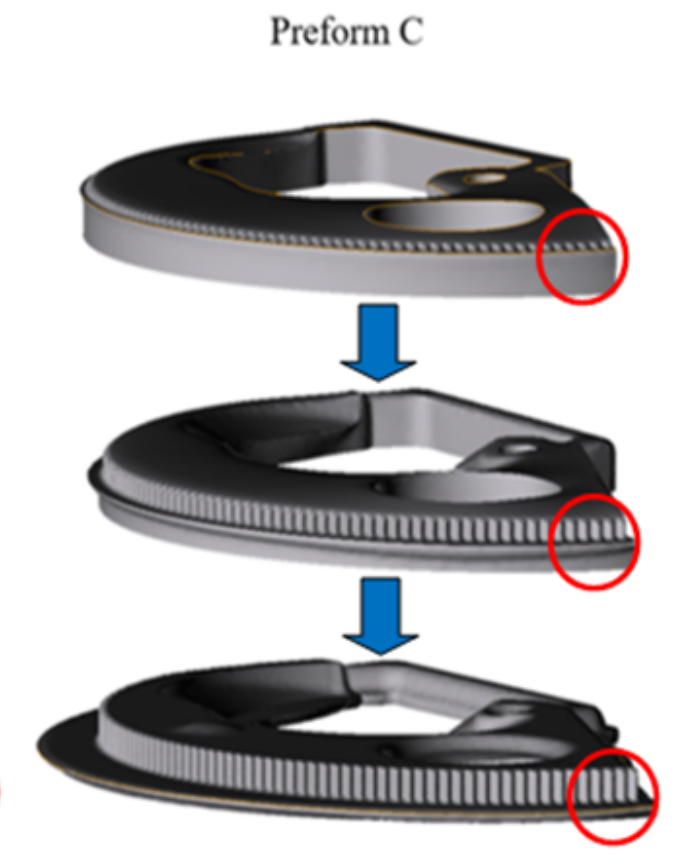

Figure 6

Different preform of the forging workpieces. (a) Preform A with extrusion process. (b) Preform B with the gear tooth on forging workpiece. (c) Preform $\mathrm{C}$ without gear tooth on forging workpiece. 


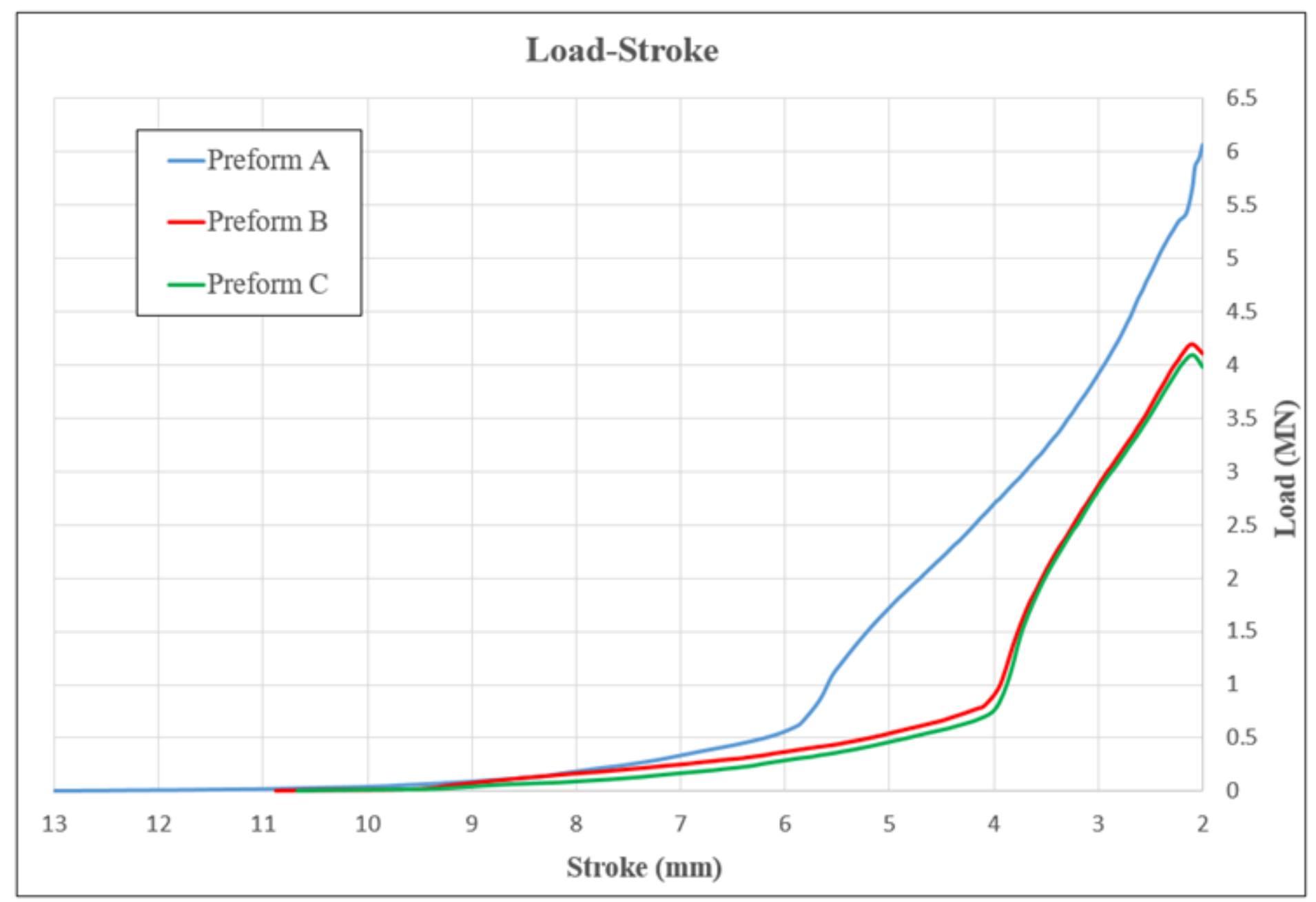

Figure 7

Load-Stroke of three unlike preforms (Preform A, Preform B, and Preform C). 
(a) Preform B

(a) $100 \%$ punch stroke

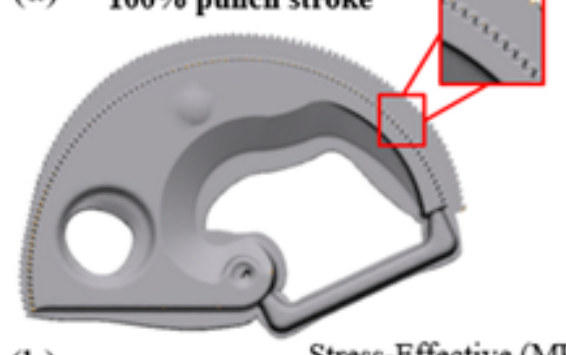

(b)

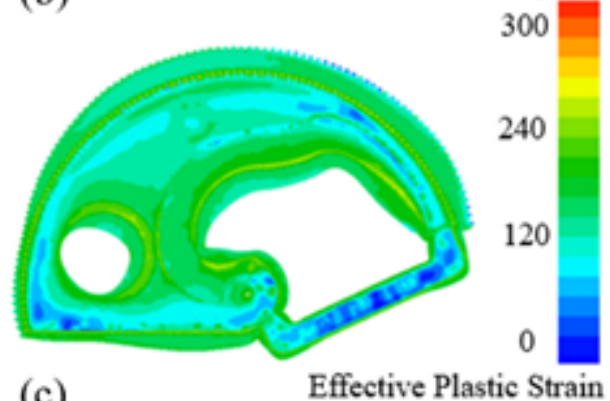

(c)

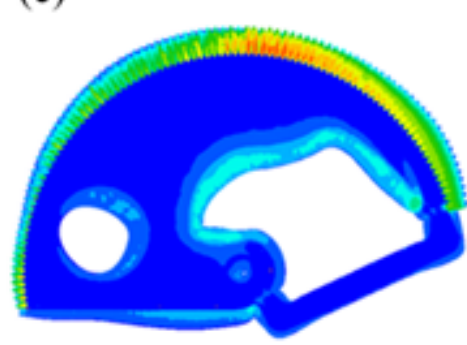

11.0

(d)

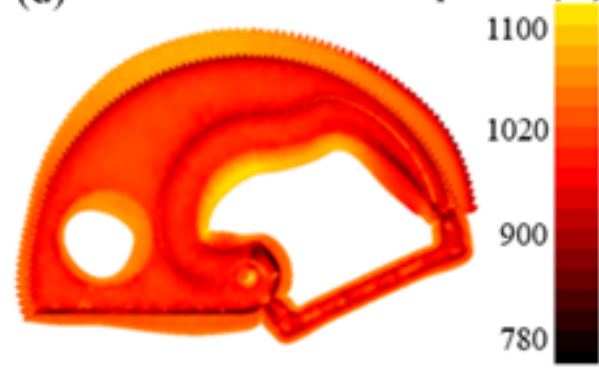

\section{Preform C}

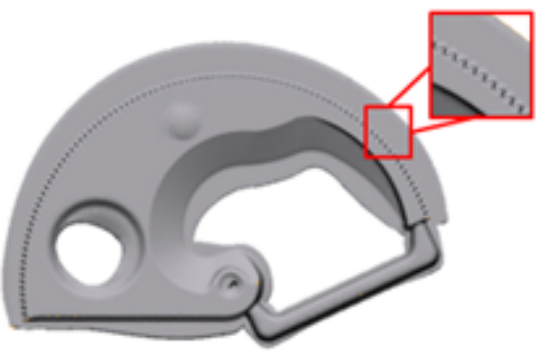

Stress-Effective (MPa) 280

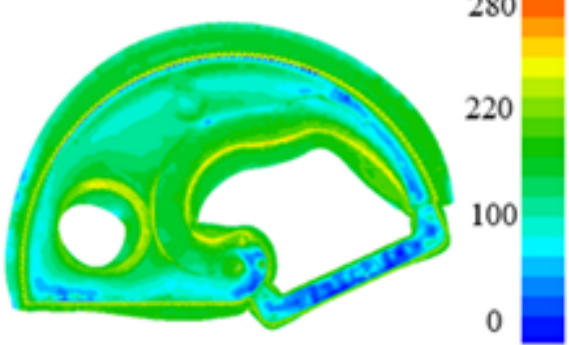

Effective Plastic Strain

9.5

6.5

3.0

0.0

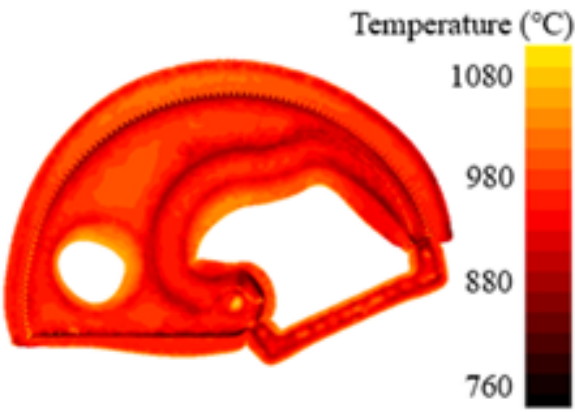

Figure 8

The simulated results of two different preform (Preform B and Preform C). (a) simulated results at 100\% punch strok respectively for (b) Effective stress. (c) Effective plastic strain. (d) Temperature. 
(a) Preform B

Preform C

(b)
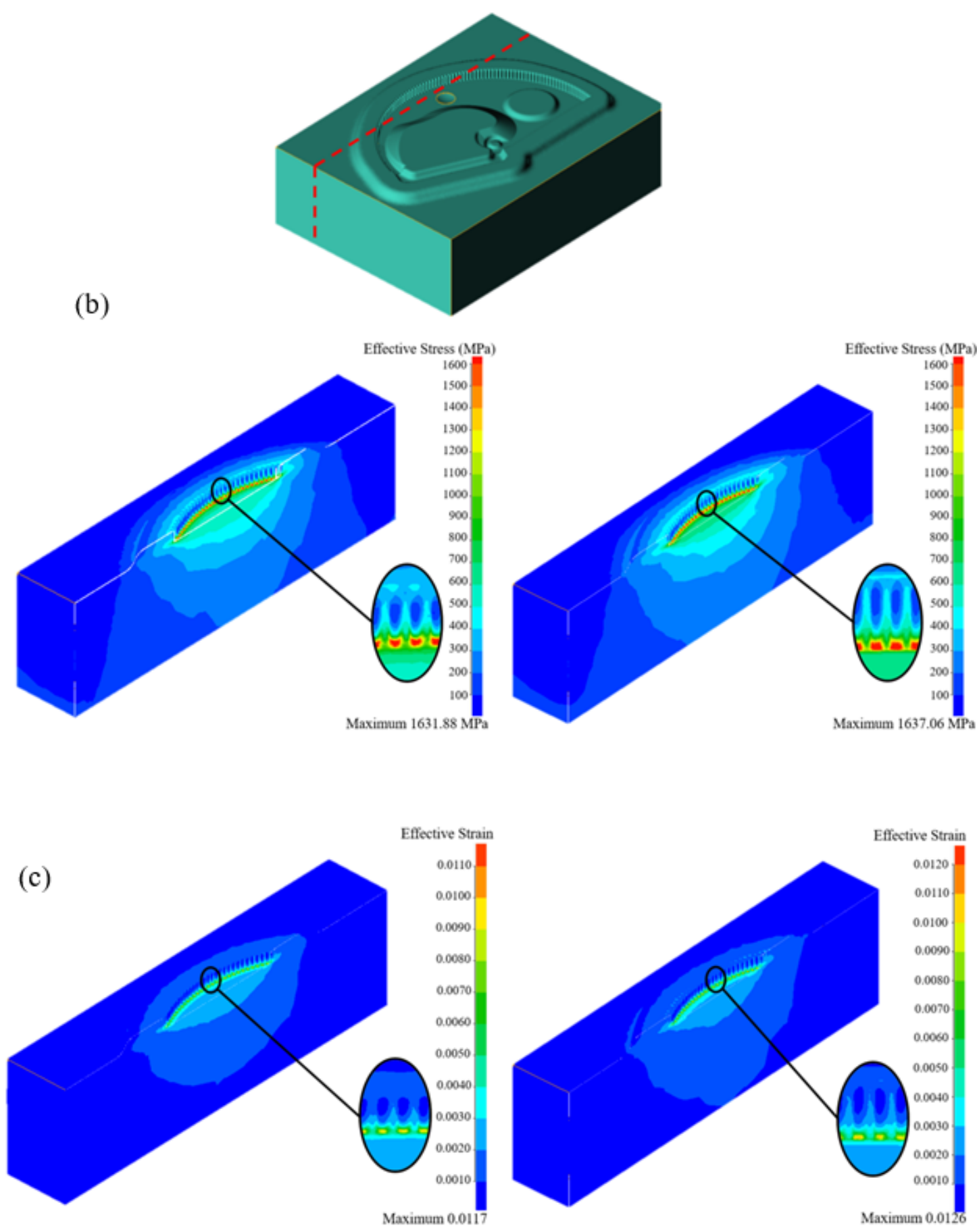

Figure 9

(a) Schematic diagram on tooth die (Preform B and Preform C) (b) The distribution of effective stress on tooth die (c) The distribution of effective strain on tooth die. 


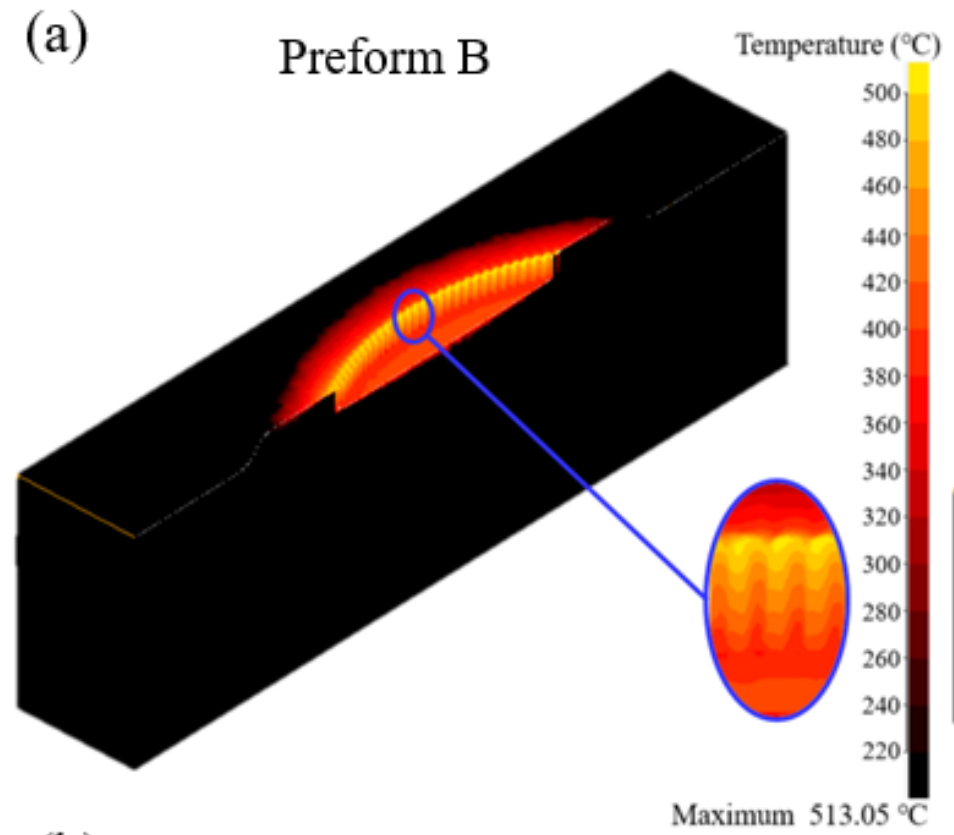

(b)

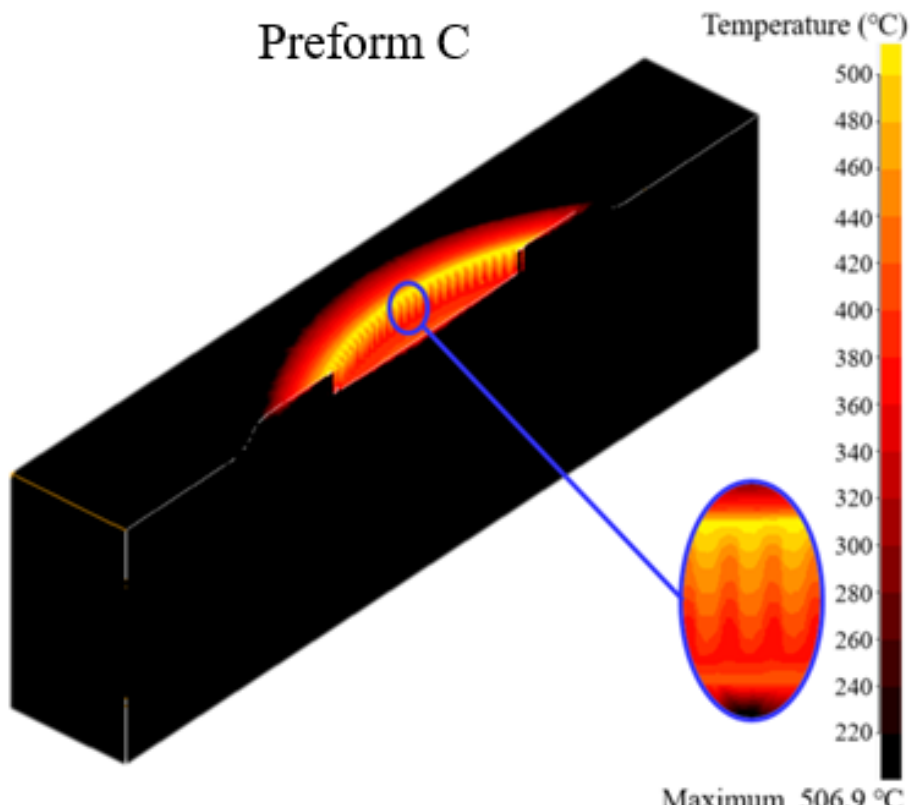

Maximum $506.9^{\circ} \mathrm{C}$
Displacement Vector (mm)

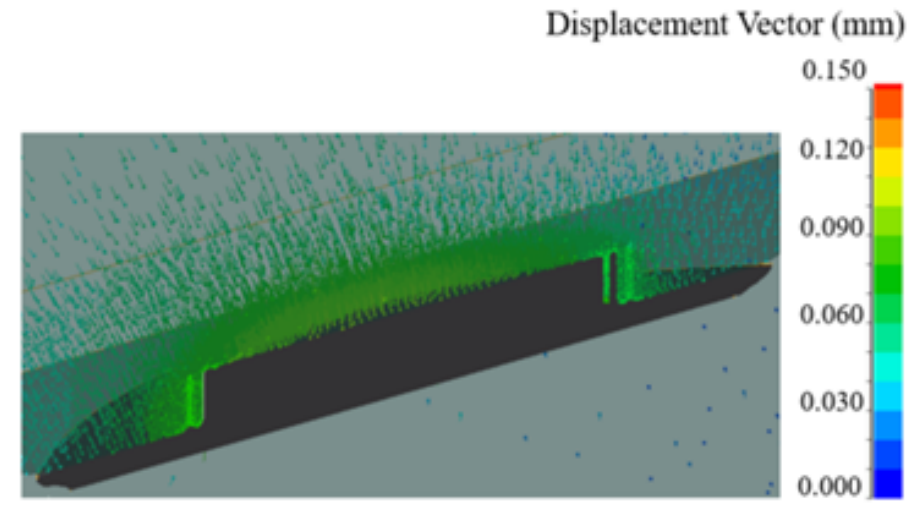

Maximum $0.1546 \mathrm{~mm}$

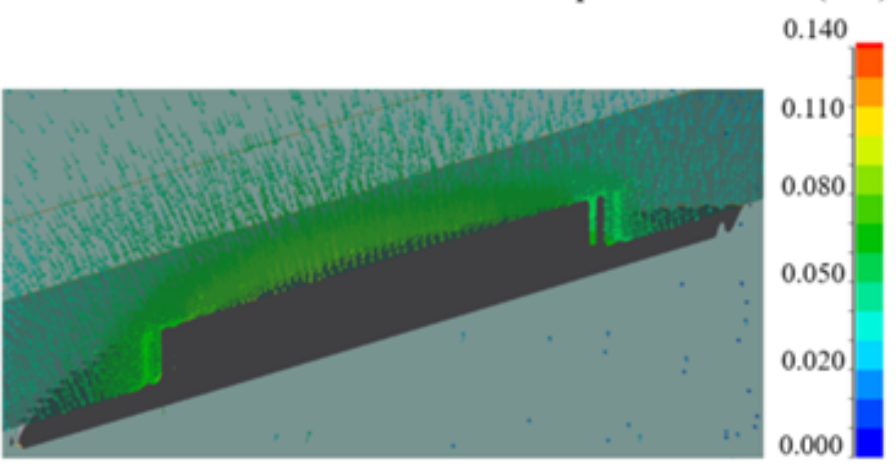

Maximum $0.1416 \mathrm{~mm}$

Displacement Vector (mm)

Maximum $0.1416 \mathrm{~mm}$

Figure 10

(a) The distribution of temperature on tooth die (b) The distribution of displacement vector on tooth die. 
(a)

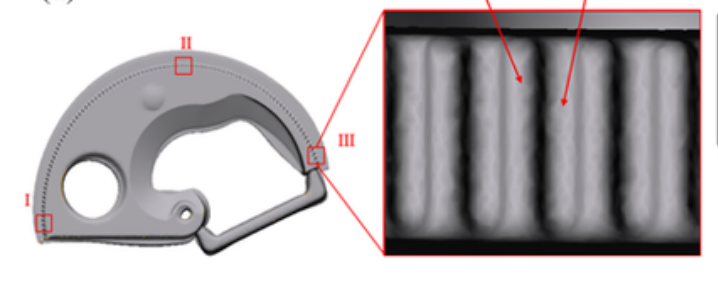
] 7

(b)

Preform B

\begin{tabular}{|c|c|c|c|c|}
\hline & Scheme & $\mathrm{H}_{\mathrm{s}}(\mathrm{mm})$ & $\mathrm{H}_{\mathrm{g}}(\mathrm{mm})$ & HFR \\
\hline \multirow{5}{*}{ 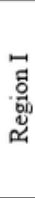 } & 1 & 6.2 & 6.3 & 0.98 \\
\hline & 2 & 6.18 & 6.21 & 0.99 \\
\hline & 3 & 6.07 & 6.14 & 0.98 \\
\hline & 4 & 6.02 & 6.05 & 0.99 \\
\hline & 5 & 5.95 & 6 & 0.99 \\
\hline \multirow{5}{*}{ 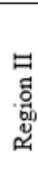 } & 1 & 6.25 & 6.3 & 0.99 \\
\hline & 2 & 6.17 & 6.21 & 0.99 \\
\hline & 3 & 6.02 & 6.14 & 0.98 \\
\hline & 4 & 6.03 & 6.05 & 0.99 \\
\hline & 5 & 5.92 & 6 & 0.98 \\
\hline
\end{tabular}

\begin{tabular}{|c|c|c|c|c|}
\hline \multirow{3}{*}{ 目 } & 1 & 6.28 & 6.3 & 0.99 \\
\cline { 2 - 5 } 芯 & 2 & 6.19 & 6.21 & 0.99 \\
\cline { 2 - 5 } 幽 & 3 & 6.11 & 6.14 & 0.98 \\
\cline { 2 - 5 } & 4 & 6.03 & 6.05 & 0.99 \\
\cline { 2 - 5 } & 5 & 5.98 & 6 & 0.99 \\
\hline
\end{tabular}

(c)

\begin{tabular}{|c|c|c|c|c|}
\hline & Scheme & $\mathrm{W}_{\mathrm{s}}(\mathrm{mm})$ & $\mathrm{W}_{\mathrm{g}}(\mathrm{mm})$ & WFR \\
\hline \multirow{5}{*}{ 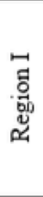 } & 1 & 0.82 & 1.02 & 0.19 \\
\hline & 2 & 0.97 & 1.05 & 0.08 \\
\hline & 3 & 1.21 & 1.25 & 0.03 \\
\hline & 4 & 1.13 & 1.14 & 0.05 \\
\hline & 5 & 1.15 & 1 & 0.08 \\
\hline \multirow{5}{*}{ 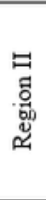 } & 1 & 0.83 & 1 & 0.17 \\
\hline & 2 & 0.95 & 1.04 & 0.09 \\
\hline & 3 & 1.23 & 1.25 & 0.02 \\
\hline & 4 & 1.09 & 1.1 & 0.01 \\
\hline & 5 & 1.03 & 1.05 & 0.02 \\
\hline \multirow{5}{*}{ 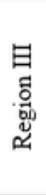 } & 1 & 0.88 & 1 & 0.12 \\
\hline & 2 & 0.96 & 1.05 & 0.09 \\
\hline & 3 & 1.2 & 1.25 & 0.04 \\
\hline & 4 & 1.16 & 1.2 & 0.03 \\
\hline & 5 & 1.08 & 1.1 & 0.02 \\
\hline
\end{tabular}

Preform C

\begin{tabular}{|c|c|c|c|c|}
\hline & Scheme & $\mathrm{H}_{\mathrm{s}}(\mathrm{mm})$ & $\mathrm{Hg}_{\mathrm{g}}(\mathrm{mm})$ & HFR \\
\hline \multirow{5}{*}{ 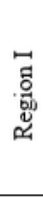 } & 1 & 6.22 & 6.3 & 0.99 \\
\hline & 2 & 6.16 & 6.21 & 0.99 \\
\hline & 3 & 6.1 & 6.14 & 0.98 \\
\hline & 4 & 6.04 & 6.05 & 0.99 \\
\hline & 5 & 5.98 & 6 & 0.99 \\
\hline \multirow{5}{*}{ 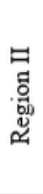 } & 1 & 6.27 & 6.3 & 0.99 \\
\hline & 2 & 6.20 & 6.21 & 0.99 \\
\hline & 3 & 6.11 & 6.14 & 0.98 \\
\hline & 4 & 6.02 & 6.05 & 0.98 \\
\hline & 5 & 5.97 & 6 & 0.99 \\
\hline
\end{tabular}

\begin{tabular}{|c|c|c|c|c|}
\hline \multirow{5}{*}{$\begin{array}{l}\text { 目 } \\
\text { 号 } \\
\text { 㟧 }\end{array}$} & 1 & 6.24 & 6.3 & 0.99 \\
\hline & 2 & 6.16 & 6.21 & 0.98 \\
\hline & 3 & 6.13 & 6.14 & 0.98 \\
\hline & 4 & 6.01 & 6.05 & 0.98 \\
\hline & 5 & 5.94 & 6 & 0.98 \\
\hline
\end{tabular}

\begin{tabular}{|c|c|c|c|c|}
\hline & Scheme & $\mathrm{W}_{\mathrm{s}}(\mathrm{mm})$ & $\mathrm{W}_{\mathrm{g}}(\mathrm{mm})$ & WFR \\
\hline \multirow{5}{*}{ 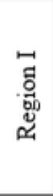 } & 1 & 0.84 & 1.02 & 0.17 \\
\hline & 2 & 0.99 & 1.05 & 0.06 \\
\hline & 3 & 1.24 & 1.25 & 0.01 \\
\hline & 4 & 1.12 & 1.14 & 0.02 \\
\hline & 5 & 1.09 & 1 & 0.13 \\
\hline \multirow{5}{*}{ 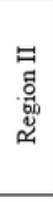 } & 1 & 0.85 & 1 & 0.15 \\
\hline & 2 & 0.92 & 1.04 & 0.11 \\
\hline & 3 & 1.22 & 1.25 & 0.02 \\
\hline & 4 & 1.09 & 1.1 & 0.01 \\
\hline & 5 & 1.04 & 1.05 & 0.01 \\
\hline \multirow{5}{*}{$\begin{array}{l}\text { 早 } \\
\text { 总 } \\
\text { ֻ }\end{array}$} & 1 & 0.91 & 1 & 0.09 \\
\hline & 2 & 0.97 & 1.05 & 0.13 \\
\hline & 3 & 1.18 & 1.25 & 0.06 \\
\hline & 4 & 1.13 & 1.2 & 0.06 \\
\hline & 5 & 1.08 & 1.1 & 0.08 \\
\hline
\end{tabular}

\section{Figure 11}

(a) Schematic region on forging workpiece and schematic location on the gear tooth (b) The evaluation index of the short section's height on preform $B$ and preform $C$. (c) The evaluation index of filling quality of gear tooth on preform B and preform C. 
(a)
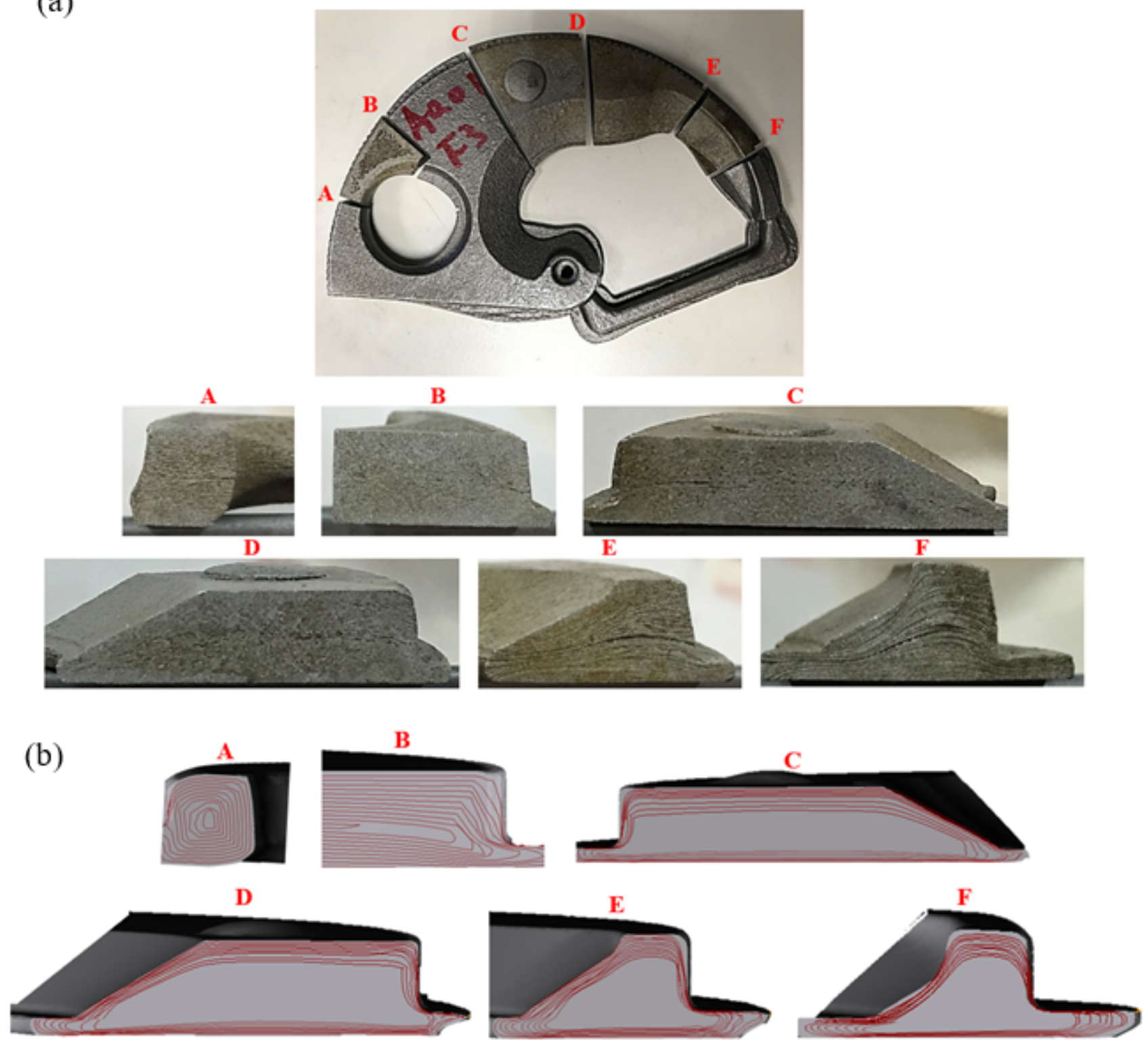

Figure 12

The forging flow lines of movable blade. (a) Schematic region on forging workpiece and the forging flow lines of the experiment (b) The forging flow lines of the simulation. 
(a)

(b)
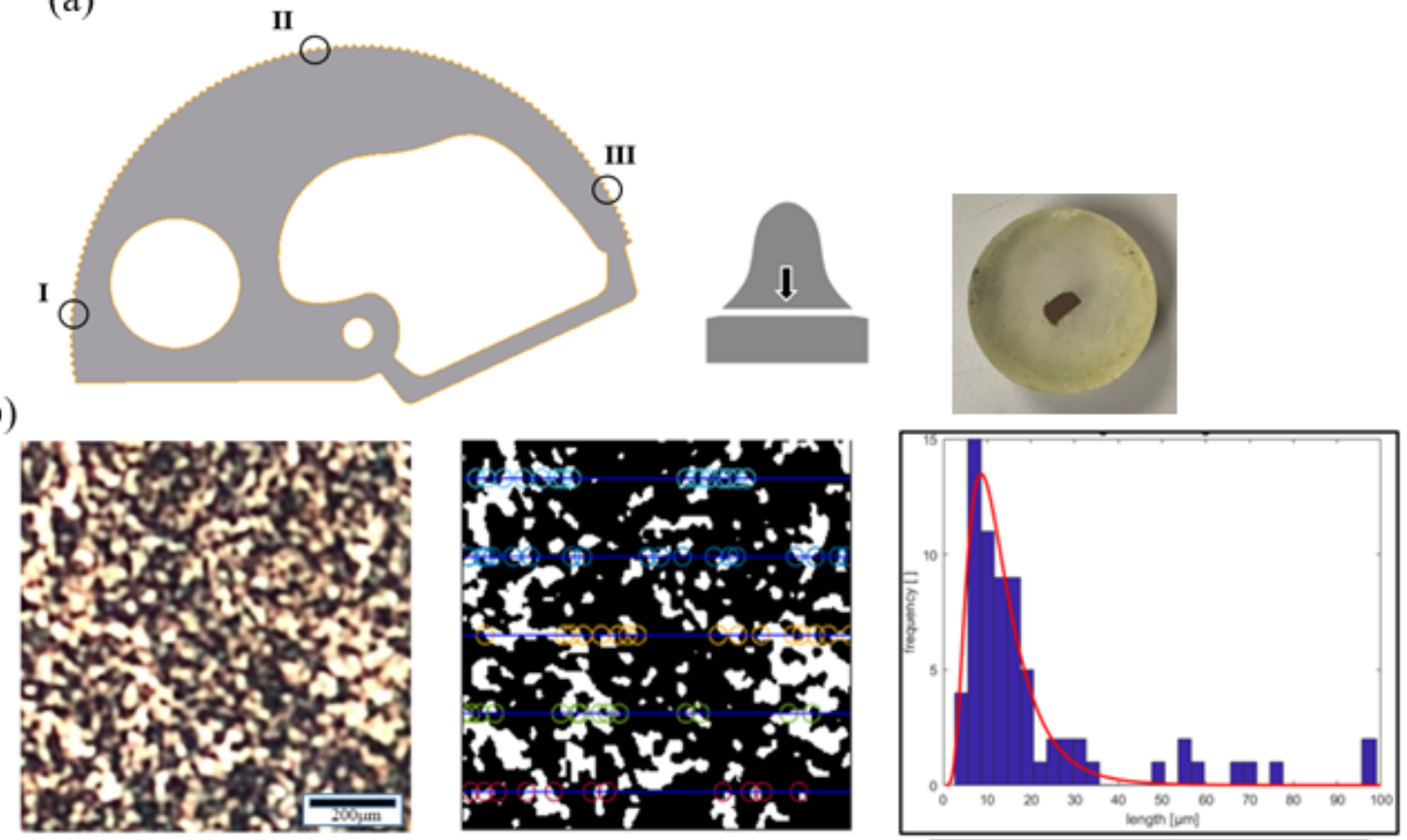

(c)
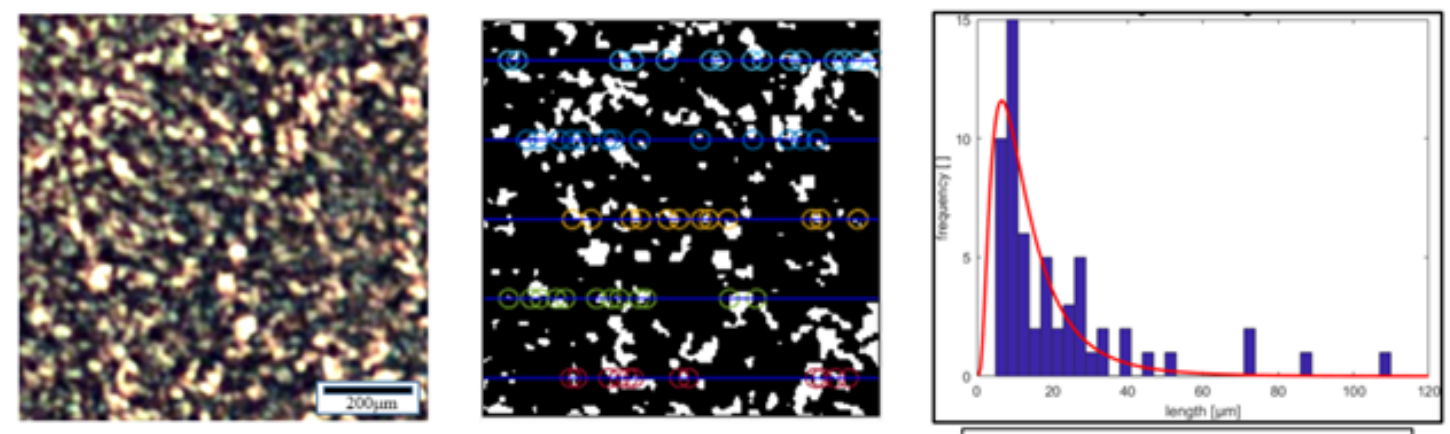

Average grain radius $=11.13$ micron

(d)
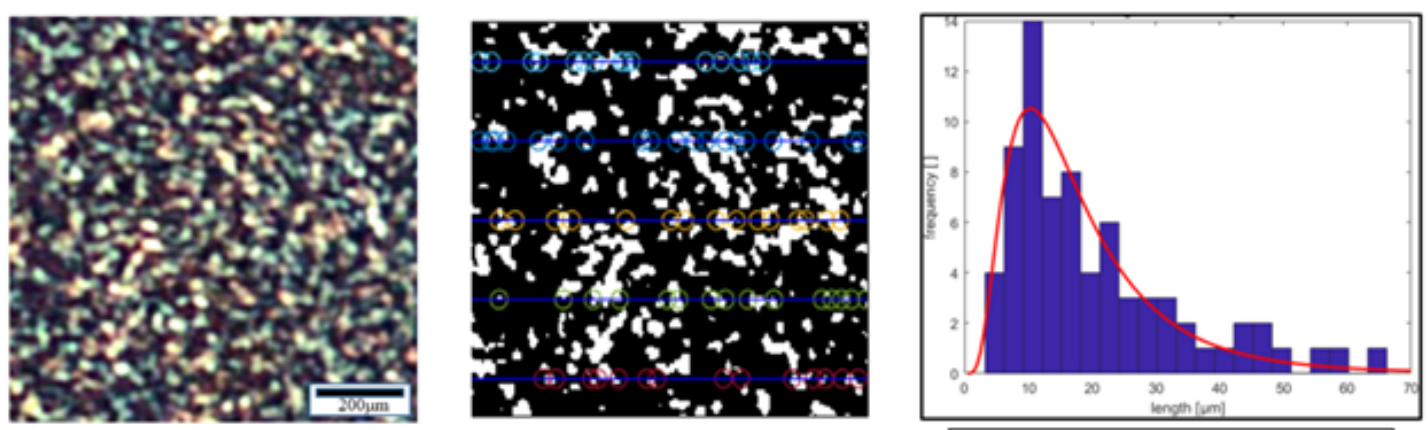

Average grain radius $=13.23$ micron

Figure 13

(a) Schematic diagram on forged gear tooth (b) The microstructure of the I region, (c) II region and (d) III region 